Institute of $\mathbf{F}_{\text {ood and }} \mathbf{A}_{\text {gricultural }} \mathbf{S}_{\text {ciences }}$

\title{
Creating A Line Of Logic In The County Plan of Work ${ }^{1}$
}

\section{Glenn Israel and Steffany Dragon ${ }^{2}$}

Effective Extension programs need to be defined with well-developed plans which identify the problem and the means for addressing that problem. The FAS2 software has been designed specifically to help Extension faculty design a sound plan of work and fulfill accountability requirements by offering a template that follows an apt line of logic. The first step in developing a sound plan of action is writing the situational statement and rationale for the program. These establish the need for the program and set the stage for specifying the program's objectives and activities.

In this paper, we will review the concept of logic and its role in developing a sound plan of work. This is followed by a discussion of the FAS2 components that define the program through logical situation and rationale statements and a description of the audience.

\section{The Concept of Logic}

For our purposes, logic has two meanings. First, logic refers to sound thinking or reasoning. This means that a situational statement needs to make sense to the reader.
Second, logic means that there is agreement between the parts or the elements. In our case, the different components of the situational statement should "fit together." One way to assess whether or not your plan is logical is to see if you write about the same topic or the same subject throughout the whole plan. The parts are connected when each piece is related to a theme or subject.

\section{Example 1: Suppose you are planning a program to increase the profits of beef cattle producers. You plan to conduct a program on effective herd record keeping practices and you discuss the potential uses of these records. To have a logical plan, you also need to say how an effective record keeping system and producer profits are related.}

Example 2: Suppose you are planning a program to prevent nitrate pollution by homeowners. You plan to conduct a program on landscaping Best Management Practices (BMPs) and you discuss the appropriate use of nitrogen fertilizer and the use of iron sulfate in place of nitrogen for the lawn. In order to have a logical plan, you also need to say how the BMPs and nitrate pollution are related.

1. This document is AEC 371 one of a series of the Agricultural Education and Communication Department, Florida Cooperative Extension Service, Institute of Food and Agricultural Sciences, University of Florida. Publication date April 2004. Visit EDIS Web Site at http://edis.ifas.ufl.edu.

2. Glenn Israel, Ph.D., Professor, and Steffany Dragon, Graduate Assistant, Department of Agricultural Education and Communication, Florida Cooperative Extension Service, Institute of Food and Agricultural Sciences, University of Florida, Gainesville, FL 32611-0540.

The Institute of Food and Agricultural Sciences (IFAS) is an Equal Employment Opportunity - Affirmative Action Employer authorized to provide research, educational information and other services only to individuals and institutions that function without regard to race, creed, color, religion, age, disability, sex, sexual orientation, marital status, national origin, political opinions or affiliations. For information on obtaining other extension publications, contact your county Cooperative Extension Service office. Florida Cooperative Extension Service / Institute of Food and Agricultural Sciences / University of Florida / Larry R. Arrington, Interim Dean 


\section{Components of a Logical Plan}

The components of a logical rationale can be effectively incorporated into a plan of work to ensure its effectiveness. There are six components in a logical rationale: 1) an organizing statement, 2) a description of the current situation, 3) a description of the preferred situation, 4) reasons for the gap or need, 5) the significance of the change, and 6) a specification of the intended audience.

\section{Situational Statements}

When using the FAS2 software to complete an Extension Plan of Work, situational statements are needed at three different levels: 1) situation for the statewide goal, 2) global situation for the focus area, and 3) local situation for the focus area. These situation statements are listed within the Program Definition section of FAS2. The statewide goal situation and the focus area global situation are written by a goal team and a focus area team, respectively. A leader or co-leader for a county program is responsible for preparing the local situation statement.

As you write your plan of work, keep these key principles in mind:

- Include each and every component in the local situation and rationale statements. You can use key word headings to serve as a checklist.

- Explicitly link the parts together. Identifying "missing links" can be the difference between programs that work as planned and those that fail to reach their objectives.

- Leave out unrelated information. Extra information can cloud reasoning and divert attention from the issue to be addressed. Including unrelated information can lead you to plan educational activities which may have no impact on the problem and divert valuable resources from more important activities.

\section{Statewide Goal}

To define a program, you must first select a Statewide Goal from the drop-down list which best matches your program (See Figure 1).

\section{Focus Area}

Once you have selected the Statewide Goal, a drop down list will contain Focus Area options that pertain to the goal you specified. You must select one (See Figure 2).

\section{Global and Local Situations}

When the statewide goal and the focus area are selected, the corresponding situational statement for goal and the focus area are displayed. Next, you should complete a local situation statement for the focus area. The local situational statement for the focus area reflects factual data that describes the severity of a set of problems or issues affecting a primary target audience of an Extension program. The data show a need or gap between what is and what could be (Ladewig, 2003). It is helpful to include an organizing statement here to set the stage.

Example 1: Increasing the profitability of beef cattle producers in Northwest Florida would bolster the state's economy.

Example 2: Decreased nitrate pollution in Northeast Florida neighborhoods would contribute to cleaner drinking water for Florida citizens.

The description of the Local Situation must be contained in a text field. It should include a description of the current situation, or what is, and the preferred situation, or what could be. The best descriptions of what is are those of practices, behaviors, and consequent conditions. The description of the current situation also should use quantitative data, if available.

Example 1: A 2002 study reveals a relatively low 55 percent record keeping rate among beef cattle producers in Northwest Florida (Mayo, et al., 2002).

Example 2: Data show limited use of two important BMPs by homeowners in Northeast Florida. Only 27 percent of Northeast homeowners are applying 1 pound or less of actual nitrogen per 1,000 square feet, and an 8 percent of homeowners in this area are applying iron sulfate on the 
lawns instead of nitrogen-containing fertilizer in the summer (Israel, 2003).

There are a number of ways to establish the criteria of the preferred situation, which is sometimes referred to as the "realistic potential". You can use research findings, adoption theory, practical experience, or comparisons to identify the preferred situation. Research findings often tell us what can happen when best management practices are used or when recommended behaviors are adopted.

Comparisons can be made using information for your county and other counties (either adjacent counties or ones with similar characteristics), the state average, or some other comparison group to identify the preferred situation.

Example 1: The whole herd record keeping percentage of Northwest beef cattle producers could be increased to the same level that exists for the nation as a whole. In 1997, 81 percent of all the beef cattle producers in the United States kept whole herd records (US Beef 97 as cited in Mayo, et al., 2002).

Example 2: Based on results from a statewide Extension program that included workshops on fertilizer BMPs, adoption of appropriate nitrogen use and iron sulfate application among Florida homeowners who participated in the program increased to 45 percent and 14 percent, respectively (Israel, et al., 1999).

\section{Global/Local Rationale}

The Global Rationale is provided for county faculty. Two components - reasons for the gap between the current and preferred situation, and the significance of the change, make up the Local Rationale. The rationale explains why the problems/opportunities related to the issue can be addressed through education. The statement describes what is known of the problems/opportunities to be addressed, practices which are currently being followed, audience(s) to be targeted, topics to be covered, subjects to be taught, and changes recommended.
This rationale will provide a basis for specifying the educational activities to be used (Ladewig, 2003). This is important because clientele needs have two dimensions: 1) a substantive problem requiring specific information and 2) a capacity for using information (Nitsch, 1982). The latter needs to be considered because the "right" information may not create change if people do not have access to it, misunderstand it, or are unable to apply it due to external constraints. Understanding why a need exists can help you identify both the focus for the educational program and the methods for delivering it efficiently. The research literature can provide valuable information about the causes and consequences of problems which Extension programs are intending to address.

Example 1: Some beef cattle producers in Northwest Florida may not realize the value in using financial and production herd data to determine success or failure. These producers might have negative perceptions about the usefulness and complexity of record keeping, and as a consequence, choose not to attend Extension programs on the topic. Attracting more producers to training sessions on keeping and using herd records can help them to adopt these practices and, in turn, increase profitability.

Example 2: Figuring out how to apply fertilizer at a rate of 1 pound or less of actual nitrogen per 1000 square feet is a complicated process for most homeowners and requires a series of calculations to do it correctly. The information on fertilizer bag labels also might be incomplete or confusing. The use of iron sulfate is not as ordinary or safe sounding a practice as leaving clippings on the lawn (another highly used BMP), for instance. Training sessions that focus on how to calculate the appropriate rate of nitrogen application and the principles and benefits behind using iron sulfate can increase the percentage of homeowners using these practices.

The significance of the change should also be contained in the rationale. It explains why the 
program is important, that is, what difference the program will make if it achieves the preferred situation.

The rationale also should provide a description of the projected impact in terms of conditions related to economic well-being, the environment, health and life quality, or civic engagement of individuals, families, organizations, or communities.

Example 1: A 2002 survey of Northwest Florida cattle producers showed that 41 percent of producers that kept herd records were profitable, while only 27 percent of producers that did not keep herd records were profitable (Mayo, et al., 2002). Keeping records shows costs and returns and enables a producer to make better decisions. This, in turn, can contribute to increased profitability.

Example 2: Excess nitrogen pollutes groundwater which is the source of drinking water for 95 percent of the states population in the state (Follet, 1989). Nitrate build-up in the body leads to a decreased rate of oxygen absorption of blood in infants (National Academy of Sciences, 1978), and may be linked to various cancers that might be associated with the conversion of nitrate to nitrosamine in the human body (Follet, 1989). A potentially significant source of nitrate pollution in groundwater is the application of nitrogen-rich fertilizers to landscapes (Bocher, 1995). Therefore, the adoption of the nitrogen-related BMPs among Northeast Florida residents can decrease groundwater pollution and ameliorate health risks linked to nitrates.

\section{Target Audience}

The sixth component, specification of the intended audience, involves identifying the target audience, primary audience, priority topics, and the projected and target number. The target audience is a broad description of the target group of learners of the Extension program. It may include how individuals or groups of people are affected by conditions within a specific geographical region. The primary audience is a more specific description of the audience, and includes demographic characteristics, Census of Agriculture data, community and business characteristics, and environmental information.

Priority topics, which encompass subject matter areas related to the issue and problems being addressed, are determined for the specific audience.

The FAS2 software gives you the opportunity to specify the target audience, primary audience, and priority topic by selecting the appropriate category from a drop-down menu (See Figure 3). For example, for the target audience you might select "producers" or "homeowners." If you chose producers, you can then choose "livestock" to specify what type of producers to identify your primary audience. You may choose a priority topic in herd management, marketing and quality, or one of the other options listed. You then must input a projected number of the target audience and then a target number that specifies whom your program plans to reach. The projected number indicates how many individuals are in the primary audience and the target number indicates how many you expect to recruit as participants for your program. Previous experience and available resources are two important considerations for identifying the target number. For example, out of 2,072 livestock producers in the Northwest Florida area, 500 may be set as the target for the BMPs priority topic (see Figure 3).

You should also identify characteristics of the audience which may affect how the program is delivered or its impact. This information should be included in the Local Rationale.

Example 1: The number of producers in the area is estimated at 2,072 (National Agricultural Statistics Service, 1997). However, data show that 58 percent of producers with 50 or more head of cattle that use records for business analysis are profitable while only 36 percent of producers with 50 or fewer head of cattle are profitable when they use records for business analysis. Therefore, extension efforts would be maximized if the program focused on the 85 larger scale producers in the area. A training program that demonstrated how to correctly keep and use herd records for business analysis 
could significantly improve the profitability of larger operations.

Instead of targeting 500 producers for marketing and quality, the plan would be to target the 85 larger operations. This should be reflected in the table (Figure 3).

Example 2: The number of single-family, occupied households in Northeast Florida is estimated at 236,929 (U.S. Census Bureau, 2000). A study comparing lawn service users and nonusers found that each group obtains information on yard maintenance differently. Nonusers receive information directly from the Extension service, while lawn care service users obtain their information from their lawn care service, or garden centers (Israel \& Knox, 2001). Given the objective is to inform whoever is applying the fertilizer about BMPs, it would be important to provide information regarding BMPs to individual homeowners and lawn care service providers. In order for lawn care professionals to take the time to share information with customers, Extension will have to demonstrate how these practices can increase customer satisfaction and loyalty, reduce operating costs and increase net profit.

Identifying characteristics of the target audience also can allow you to segment your audience into groups that have the same information needs (in the same way that marketing firms have used so successfully to sell products). Identifying audience segment helps you get the right information to the right people. It is also important to use the right methods to deliver that educational program, because some people use different methods to get information from other people (Israel, 1991).

\section{Summary}

Applying the idea of logic to program planning can improve the entire program process and lead to measurable impacts. Logic means that the rationale includes all of the necessary parts for a program and that each piece fits in with the others. Logic also means that only relevant information is included; the extra "stuff" is left out. In specifying most components, a single sentence can provide the sufficient amount of information. But for other components, you may need several sentences or a paragraph to provide the necessary linkage between the parts. The FAS2 software was designed with the concept of logic in mind and can serve to guide the creation of a sound plan of work for your county.

\section{References}

Israel, G.D. 1991. Reaching extension's clientele: Exploring patterns of preferred information channels among small farm operators." Southern Rural Sociology. $8(1): 15-32$.

Ladewig, H.L. 2003. Definitions. Unpublished.

Nitsch, U.1982. Farmers perceptions of and preferences concerning agricultural extension programs. Uppsala, Sweden: Department of Economics and Statistics, Swedish University of Agricultural Sciences, Report 195.

\section{Examples References}

Bocher, L.W. 1995. Tracing the flow of chemicals: How to reduce nitrate pesticide leaching, Turf Science, p. 64-67.

Follet, R.F. 1989. Nitrogen Management and Groundwater Protection. New York, NY: Elsevier.

Israel, G.D. 2003. Northeast Florida yards and neighborhoods pre-program data. Unpublished.

Israel, G.D., \& Knox, G.W., 2001.Reaching diverse homeowner audiences with environmental landscape programs: Comparing lawn service users and nonusers, Proceeding of the SNA Research ConferenceJanuary, 46:458-460.

Israel, G.D., Easton, J.O., \& Knox, G.W. 1999. Adoption of landscape management practices by florida citizens." HortTechnology. 9(2):262-266. 
Mayo, D., Israel G.D., and Vergot, P. 2002.

2002 Northwest florida beef \& forage survey summary. Cooperative Extension Service,

IFAS, University of Florida.

National Academy of Sciences (NAS). 1978.

Nitrates: An environmental assessment.

Washington, D.C.: NAS

National Agricultural Statistics Service. 1997.

1997 Census of Agriculture - Florida.

U.S.Census Bureau. 2000. Census 2000

summary file 3 (SF-3)- sample data. 
Figure 1. Statewide Goal list.

\begin{tabular}{l}
\hline --Select Statewide Goal-- \\
I. To enhance and maintain agricultural and food systems \\
II. To maintain and enhance Floridas environment \\
III. To develop responsible and productive youth through 4-H and other youth \\
programs \\
IV. To create and maintain Florida friendly landscapes: The smart way to grow \\
V. To assist individuals and families to achieve economic well-being and life quality \\
VI. To achieve economic prosperity and community vitality in Floridas urban and rural \\
communities \\
VII. To promote professional development activities designed to enhance \\
organizational efficiency and effectiveness
\end{tabular}

Figure 2. Focus Area Drop-down Menu.

--Select Focus Area--
Florida Yards and Neighborhoods (FYN)
Commercial Horticultural/Urban Forestry Services
The Importance of Diagnostic Tools
Master Gardeners
Residential Landscapes
Green Industry Best Management Practices (BMPs)

Figure 3. Audience Information

\begin{tabular}{|l|l|l|l|l|}
\hline \hline \multicolumn{4}{|l|}{ Audiences/Topics } \\
Target & Primary & Priority & Projected & Target \\
Audience & Audience & Topic & Number & Number \\
Producers & Livestock & BMPs & 2,072 & 500 \\
Producers & Livestock & $\begin{array}{l}\text { Marketing } \\
\text { and } \\
\text { Quality }\end{array}$ & 2,072 & 85 \\
& & & \\
\hline \hline
\end{tabular}

